\title{
Spore Morphology and Systematics of the Genus Christensenia
}

\author{
Cristina Rolleri; María C. Lavalle; Adriana Mengascini; Mónica Rodríguez
}

American Fern Journal, Vol. 86, No. 3. (Jul. - Sep., 1996), pp. 80-88.

Stable URL:

http://links.jstor.org/sici?sici=0002-8444\%28199607\%2F09\%2986\%3A3\%3C80\%3ASMASOT\%3E2.0.CO\%3B2-G

American Fern Journal is currently published by American Fern Society.

Your use of the JSTOR archive indicates your acceptance of JSTOR's Terms and Conditions of Use, available at

http://www.jstor.org/about/terms.html. JSTOR's Terms and Conditions of Use provides, in part, that unless you have obtained prior permission, you may not download an entire issue of a journal or multiple copies of articles, and you may use content in the JSTOR archive only for your personal, non-commercial use.

Please contact the publisher regarding any further use of this work. Publisher contact information may be obtained at http://www.jstor.org/journals/amfernsoc.html.

Each copy of any part of a JSTOR transmission must contain the same copyright notice that appears on the screen or printed page of such transmission.

The JSTOR Archive is a trusted digital repository providing for long-term preservation and access to leading academic journals and scholarly literature from around the world. The Archive is supported by libraries, scholarly societies, publishers, and foundations. It is an initiative of JSTOR, a not-for-profit organization with a mission to help the scholarly community take advantage of advances in technology. For more information regarding JSTOR, please contact support@jstor.org. 


\title{
Spore Morphology and Systematics of the Genus Christensenia
}

\author{
Cristina Rolleri, Maria C. Lavalle, Adriana Mengascini, and \\ MÓNICA RODRIGUEZ \\ Laboratorio de Estudios de Anatomía Vegetal Evolutiva y Sistemática, \\ Museo de La Plata, Paseo del Bosque, 1900 La Plata, Argentina
}

\begin{abstract}
The spores of Christensenia are monolete, echinate, and superficially similar. However, detailed SEM study reveals differences in spore shape, size, and exospore characters, such as spine distance, length, curvature, banding, apex morphology, and fusion. These differences are taxonomically significant and correlate completely with characters of gross morphology in the three taxa in the genus.
\end{abstract}

In a recent revision, Rolleri (1993) segregated the genus Christensenia Maxon into the following taxa: C. aesculifolia Blume subsp. aesculifolia, C. aesculifolia Blume subsp. korthalsii (de Vriese) Rolleri, and C. lobbiana (de Vriese) Rolleri. In that paper, spore morphology was considered to be unimportant taxonomically, and spores were only described as "monolete, elliptic in polar view, with a conical/spinulose ornamentation of close, short, sharp but soft spine-like processes" (Rolleri, 1993, p. 14).

Later observations of Christensenia spores, however, suggested that they varied more than previously thought. Therefore, we decided to study spores with a scanning electron microscope (SEM), especially to search for possible correlations with the morphological data presented by Rolleri (1993). This is the first analysis of specific and infraspecific variation within a genus of Marattiales, although spores of extant genera and species of the order have been studied and described for well over a century.

Previous studies involving Christensenia considered it to be monotypic, and descriptions and illustrations of its spores were always attributed to C. aesculifolia (Edrtmann and Sorsa, 1971; Morucchio, 1973; Devi, 1977; Hill and Camus, 1986; Tryon and Lugardon, 1990). Erdtman and Sorsa (1971) described apparently monolete perispores having an outer wall densely ornamented with spines. Morucchio (1973) described trilete, echinate spores and the possible presence of a perispore. Devi (1977, p. 99) described the spores as monolete and "devoid of perine, with inconspicuous laesura." Hill and Camus (1986) stated that the spores may be trilete, monolete, or alete within a single synangium. They also described ornamentation as being prominently spinulose, with large spines, a feature of the sporoderm that they considered derived in the Marattiales. Tryon and Lugardon (1990, pp. 38, 42) described echinate spores with prominent, dense spines, with a seemingly linear aperture. Their use of TEM revealed an exospore of three layers and a perispore including fine, parallel laminae. 


\section{MATERIALS AND METHODS}

Samples of spores for SEM micrographs were taken from the same specimens studied for the revision of Christensenia (Rolleri, 1993) and were selected from different localities for each species and subspecies. To minimize the risk of contamination and the excessive use of herbarium specimens, two or three undehisced synangia were taken from the laminae with a moistened needle-knife and placed on double-sided cellotape. The synangia were then split open onto the adhesive surface. The remains of the synangial walls were wiped away from the tape with a very fine watercolor brush. This procedure was repeated with each sample, using clean instruments every time. Spores were untreated and were covered with gold under vacuum, and SEM micrographs were taken at the Laboratorio de Microscopia Electrónica of the Museo de La Plata. Standard magnifications were used for viewing each sample: $\times 2000$ and $\times 3500$ for spores, $\times 5000$ for laesurae, and $\times 10,000$ and $\times 20,000$ to illustrate variations of the echinate ornamentation, details of the morphology of the spines, and sections of the exospore in abraded spores.

\section{Spore SHAPE, Size, AND APERTURES}

The spores of Christensenia are elliptic or circular in polar view and slightly reniform in lateral view (Fig. 1). Ellipsoidal spores, always elliptic in polar view, are found in C. aesculifolia subsp. aesculifolia (Fig. 1A, B) and in $C$. lobbiana (Fig. 1E, F), the latter having somewhat larger dimensions (approximately $40 \times 34 \mu \mathrm{m}$ and $44 \times 34 \mu \mathrm{m}$, respectively). Spheroidal spores, circular, subcircular, or rarely elliptic in polar view, are present in C. aesculifolia subsp. korthalsii (Fig. 1C, D) and in C. aesculifolia subsp. aesculifolia from the Solomon Islands (Fig. 1G, H). Subspecies korthalsii has the smallest spores (30 $\times 28 \mu \mathrm{m}$ to $33 \times 33 \mu \mathrm{m}$ ), a size proportion that holds in specimens throughout the area. Spores of specimens of $C$. aesculifolia subsp. aesculifolia from the Solomon Islands are almost twice larger than the largest otherwise recorded for the genus $(52 \times 50 \mu \mathrm{m}$ to $55 \times 54 \mu \mathrm{m})$. According to Braithwaite's (1977) observation, this material is tetraploid, but it was not separated from the type subspecies by Rolleri (1993), because the external and internal morphological characters of plants did not reflect the higher ploidy described.

The laesura is linear and relatively long, reaching about two-thirds of the total length of spore. It appears as a thin lip or rim, sometimes obscured by the ornamentation of the exospore. It is more obvious in spores of $C$. aeculifolia subsp. korthalsii (Fig. 1D) than in spores of subsp. aesculifolia (Fig. 1B) or of $C$. lobbiana (Fig. $1 \mathrm{~F}$ ), doubtless because of the lesser density and length of the spines in subsp. korthalsii.

Among the taxa, only monolete spores were found, with no trilete, aborted, or deformed spores. The possibility of finding alete spores cannot be totally discarded because of potential masking of the thin laesura by the exospore, but the proportion of such spores would surely be statistically very low. SEM studies showed evidence of some channels in apparently alete spores, or in 

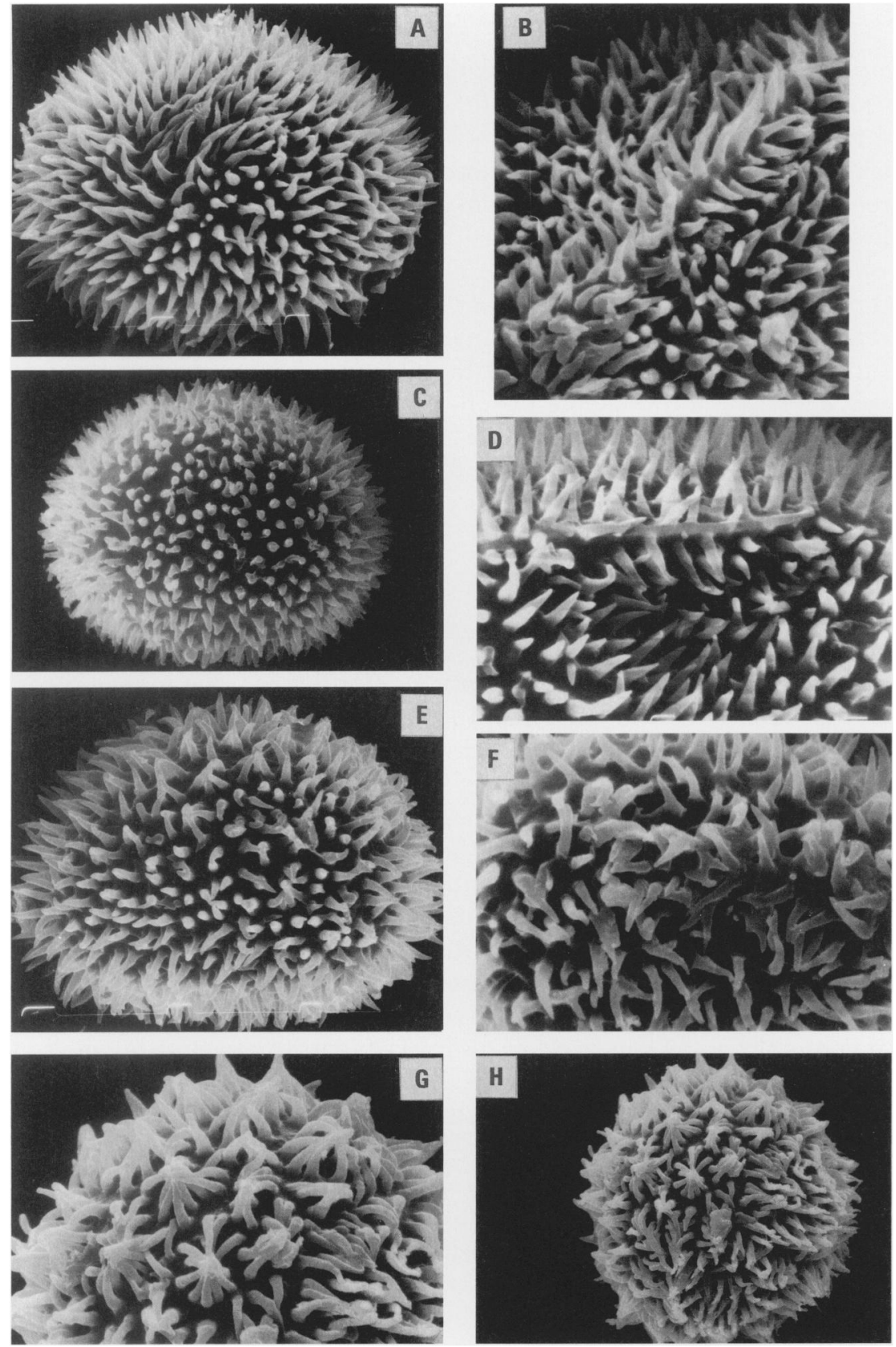

Fig. 1. Spores of Christensenia. A, B) C. aesculifolia subsp. aesculifolia from Java (Zollinger 1902, P); A) polar view, B) laesura. C, D) C. aesculifolia subsp. korthalsii from Assam (Griffith s.n., P; Mann s.n., P); C) polar view, D. laesura. E, F) C. lobbiana from the Philippines (Robinson 17914, P); E) polar view, F) laesura. G, H) C. aesculifolia subsp. aesculifolia from the Solomon Islands (Braithwaite 4220, P); G) polar view, half spore, H) same, complete spore. Magnifications: A, C, E, G) $\times 1850$; B, D, F) $\times 2650$; H) $\times 1060$. 
cases where the laesura was apparently covered by dense ornamentation. The channels are triangular in section and may correspond to the partially opened aperture, as in the case illustrated by Tryon and Lugardon (1990, p. 49) in Danaea.

\section{SPORE WALL STRUCTURE}

In spores of Christensenia, the sporoderm consists of three layers: (a) endospore, an inner pectocellulosic layer that lies between the cytoplasm contents of the spore and the exospore; (b) exospore, a middle sporopollenin layer, external to the endospore and internal to the perispore; and (c) perispore, an outer sporopollelin layer of the spore wall that is deposited on the exospore by tapetal disintegration during spore formation.

The endospore is a very thin, nitid layer to which numerous, large, round, discrete lipidic granules, which are opaque when seen with SEM, are adhered.

The exospore is relatively the thickest layer and the most important one with relation to the observed morphological variation. It is sparsely to densely ornamented with prominent, conical spines. The thickness of the exospore varies from about $1 \mu \mathrm{m}$ to about $4.5-5 \mu \mathrm{m}$.

The perispore appears as a continuous, thin layer deposited on the exospore according to its ornamentation. SEM shows it as a discrete layer, as observed in section, and as even to irregularly undulate in surface analyses. Its continuity and laminar structure were confirmed by Tryon and Lugardon (1990) using TEM in spore sections. SEM demonstrated that it is continuous, and not sparse or partial, as previous studies seemed to suggest (Hill and Camus, 1986).

\section{EXOSPORE MORPHOLOGY AND VARIATION}

The exospore is sparsely to very densely echinate (Fig. 2). The spines are generally long, usually 3-7 times longer than their basal width, although short spines with a length:basal width ratio as low as 1:1 occasionally occur. The base of the spines is rounded and wide; the body is massive, compact, conical, and either straight and erect or else curved for the distal $1 / 2$ or $2 / 3$ of its length; in some cases it is markedly banded. The apex of the spines may be acute, obtuse, incurved as hooks, slightly bifid, or bifurcate.

Although the spines are the predominant ornamentation, in some taxa nonspiny, long, clavate or baculate processes are mixed randomly among the spines. Spine density varies from bases that are contiguous to those that are distant and allow the details of the undulate perispore between the spines to be seen. The variations observed in the echinate-spinulose exospores fall into four types:

(1) Spines dense, all 3-4 times longer than their basal width, interspersed with a few others of lesser length and width (seen especially in exospore crosssections (Fig. 3A-C), none fused. Bases of the spines contiguous, wide, and rounded; bodies massive, erect or slightly curved, and sometimes irregularly banded; apices attenuate and nearly obtuse, or terminating in a small, twisted 
mucro or incurved hook (Fig. 2A-C). This type of ornamentation is characteristic of $C$. aesculifolia subsp. aesculifolia, and was observed in material from the entire range, except for specimens from the Solomon Islands.

(2) Spines rather dense, 5-6(7) times longer than their basal width, interspersed with others of lesser length and width and with, long, clavate or baculate processes in a random pattern (Fig. 2G, H), the spines also fused among themselves to a diverse degree, with free spines among groups of fused spines. Bases of the spines somewhat separate; bodies erect or diversely curved in both free and fused spines (Fig. 2G-J); apices attenuate and acute, obtuse, hooked, or sometimes bifid to bifurcate at the apex (Fig. 2I, J). This irregular, echinate-spinulose ornamentation is characteristic of the spores of $C$. lobbiana (Fig. 2G-J).

(3) Spines not dense, all 2-3 times longer than their basal width. Bases of the spines wide, rounded, and quite distant (Fig. 2D-F), revealing the undulating perispore surface (Fig. 2E), none fused with other types of spines or processes. Bases of the spines rather distant; bodies massive, generally curved, and regularly banded (Fig. 2F); apices acute, obtuse, or shortly mucronulate (Fig. 2D-F). This type of exospore is characteristic of $C$. aesculifolia subsp. korthalsii.

(4) Spines sparse, all 6-7 times (sometimes more) longer than their basal width, commonly fused at their apices in groups of 8-10 or more (Fig. $2 \mathrm{~K}-\mathrm{M}$ ). Bases of the spines set evenly apart, rounded; bodies massive, curved, rarely banded; apices of free spines attenuate, terminating in a slight hook or swelling. The fused spines forming vaulted stuctures alternating with free spines (Fig. 2K) constitute a distinctive and characteristic type of ornamentation found only in spores of tetraploid specimens of C. aesculifolia subsp. aesculifolia from the Solomon Islands.

As revealed by SEM, the sections of all these exospores vary in thickness. Those of spores of tetraploid material of $C$. aesculifolia subsp. aesculifolia (Fig. $3 G, H$ ) are 1.5-2.0 times thicker than for diploid spores from other areas (Fig. $3 \mathrm{~A}-\mathrm{C})$.

\section{KEY TO THE SPORES OF CHRISTENSENIA}

1. Exospores with all spines 2-3 times longer than their basal width; spines distant and always free, their bodies banded, incurved or more rarely erect; spores predominantly circular in polar

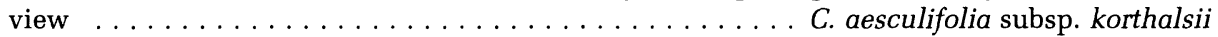

1. Exospores with at least some spines 3-7 times longer than their basal width; spines mostly dense (rarely distant) and free or fused, their bodies rarely banded, incurved or erect.

2. Spines generally fused in groups of 8-10 or more laterally or at their apex, intermingled with a few free spines as long as the fused ones, their bases mostly approximate; shorter spines having a 1:1 length:basal width ratio lacking; spores 1.5-2 times larger than all others and circular in polar view ...... C. aesculifolia subsp. aesculifolia (Solomon Isls. only)

2. Spines mostly free, a few fused in groups of fewer than 8 laterally or at their apex, their bases mostly contiguous; shorter spines having a 1:1 length:basal width ratio mixed with the longer spines.

3. Longer spines generally erect, 3-4 times longer than their basal width, not mixed with clavate or stelate (baculate) processes, free; apices acute, obtuse or hooked; spores sub- 

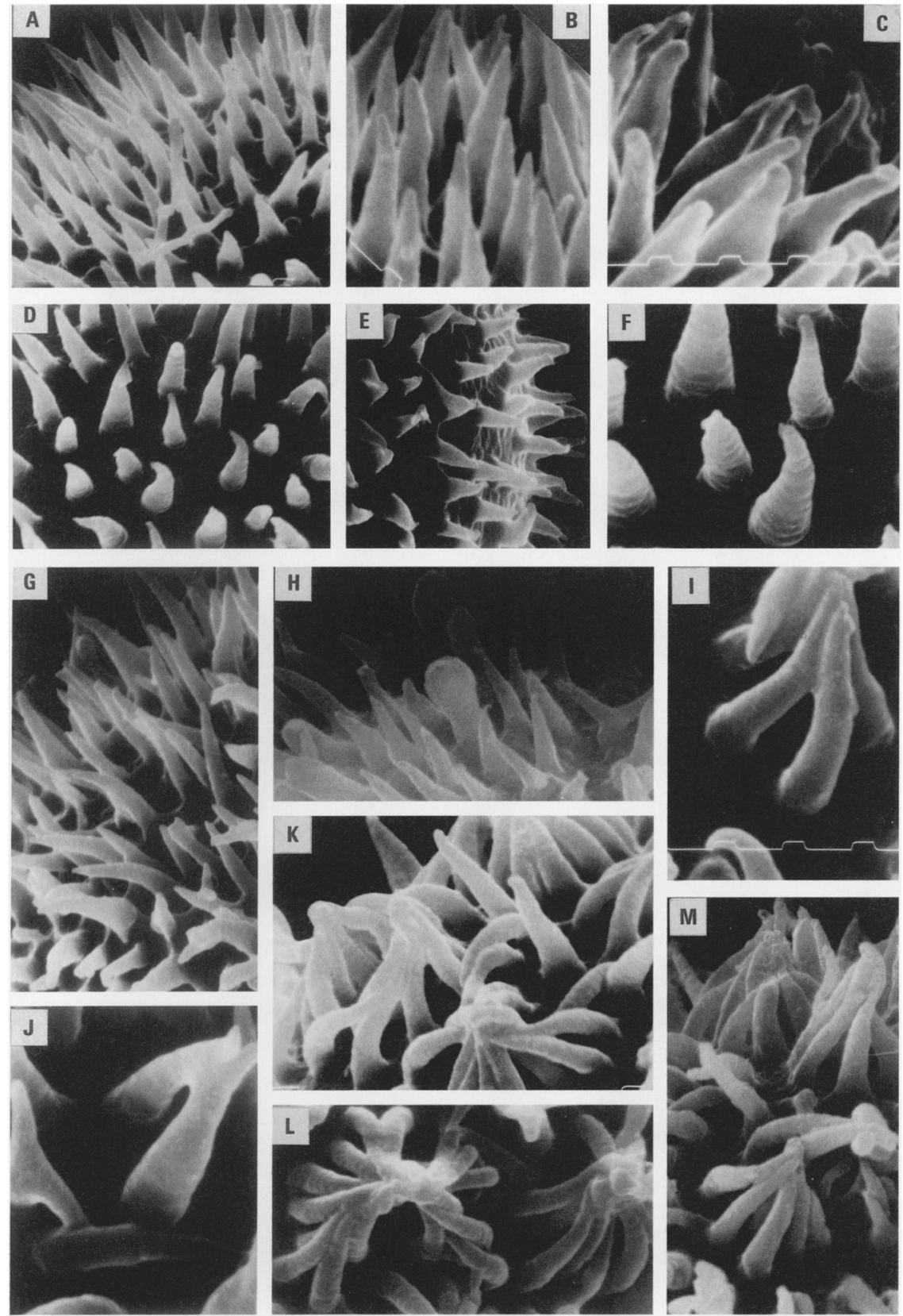

FIG. 2. Exospore types in Christensenia. A-C) C. aesculifolia subsp. aesculifolia from Java (Zollinger 1902, P). D-F) C. aesculifolia subsp. korthalsii from the Philippines (Ridley 14244, P). G-J) C. lobbiana from the Philippines (Robinson 17914, P; Edaño 36839, P). K-M) C. aesculifolia subsp. aesculifolia from the Solomon Islands (Braithwaite 4220, P). Magnifications: A, D, E, G, H, K-M) $\times 4700$; B, C, F, I, J) $\times 9400$. 

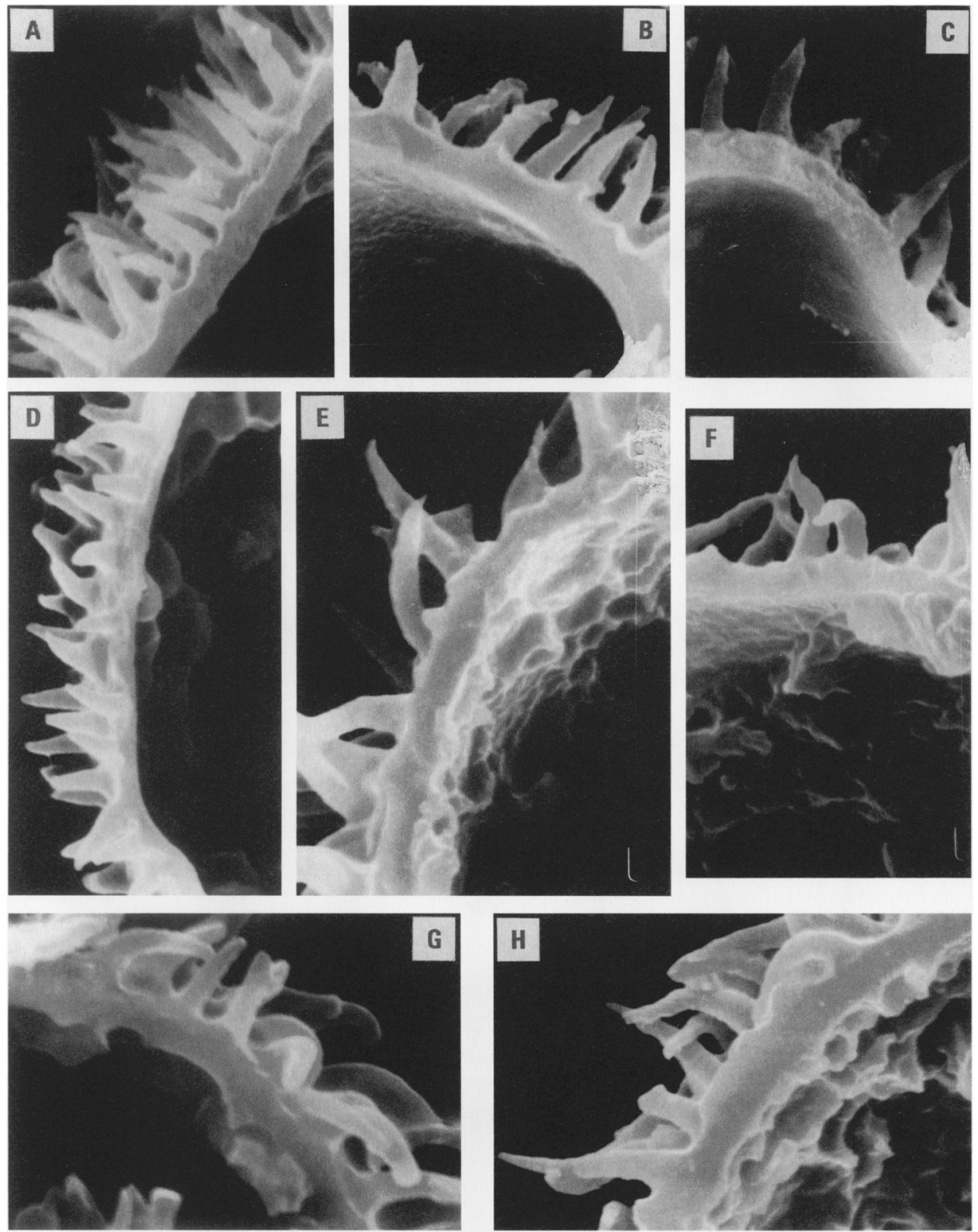

Fig. 3. Sporoderm cross-sections in Christensenia. A-C) C. aesculifolia subsp. aesculifolia from Java (Zollinger 1902, P). D) C. aesculifolia subsp. korthalsii from Assam (Mann s.n., P). E, F) C. lobbiana from the Philippines (Edaño 36839, P). G, H) C. aesculifolia subsp. aesculifolia from the Solomon Islands (Braithwaite 4220, P). Magnifications: A-H) $\times 5700$. 
circular to almost elliptic in polar view $\ldots \ldots \ldots \ldots$. . . . . . . aesculifolia subsp. aesculifolia (except Solomon Islands)

3. Longer spines generally bent, 5-6 times longer than their basal width, mixed with clavate or stelate (baculate) processes, free or occasionally fused by their apices; free apices acute, obtuse, bifid, or bifurcate; spores predominantly ellipsoidal in polar view . . . C. lobbiana

\section{CONCLUSIONS}

The spores of Christensenia are monolete and echinate (the latter a generic character in the family), with ornamentation of prominent, long and sometimes short spines formed by the compact exospore. The perispore covers the exospore as a thin layer with an irregular or undulate surface. Although other genera of Marattiales have echinate sporoderms (Archangiopteris, Danaea, and Protomarattia), the greater length and development of the spines is characteristic of Christensenia. The morphology of the spines, their relative length, dense or sparse distribution, types of apices, bending of bodies, and degree of fusion, as well as their random combination with other non-spiny processes, are characters that vary at the specific and infraspecific levels and coincide with the taxonomic categories proposed by Rolleri (1993).

The spores, either ellipsoidal or circular in polar view, do not show deformations or abortions. No mixture of spores was observed in a single synangium. The laesura is always linear, although the spine-like processes may obscure its presence. Throughout different localities, there exists a high degree of stability in the spore characters of the species and subspecies.

The differences in the characteristics of the spores allow one to distinguish tetraploid from diploid specimens of $C$. aesculifolia subsp. aesculifolia. The former are 1.5-2 times larger than the latter and exhibit a fusion of their spines. Despite these differences, we do not propose to segregate the tetraploids taxonomically, because they do not exhibit any other discrete morphological traits that allow one to distinguish them from diploid plants. Segregation carried out on the basis of spore characters alone seems somewhat artificial. The larger size of the spores does not coincide with larger or more developed plants. But, it is worth mentioning that cases of neoteny are marked in other genera of Marattiales, such as Danaea. Christensenia may provide another such case: Tetraploid plants of $C$. aesculifolia subsp. aesculifolia from the Solomon Islands tend to be smaller than diploid plants from other localities, but may be precociously fertile.

Christensenia (together with Danaea) appears to be an advanced genus of the Marattiales. The palmate, ternate or simple fronds, radial synangia, specialized porocyclocitic stomata (Rolleri et al., 1994), glandular indument, complex perispore (sensu Tryon and Lugardon, 1990), and variably and prominently echinate spores seem to be derived traits within the order.

\section{ACKNOWLEDGMENTS}

This research was carried out at the Laboratorio de Estudios de Anatomía Vegetal Evolutiva y Sistemática (LEAVES), Museo de La Plata, La Plata, Argentina, thanks to grants allotted by the 
Universidad de La Plata. Thanks are due to David Lellinger, U.S. National Herbarium, for numerous suggestions, and to Martha Morbelli, Laboratorio de Palinologia, Museo de la Plata, for valuable literature on spores of Pteridophyta. Virginia Dubarbier de Natoli (CONICET) prepared the figures.

\section{LITERATURE CITED}

BRAITHWAite, A. F. 1977. A chromosome count and range extension for Christensenia (Marattiaceae). Amer. Fern J. 67:49-50.

Devi, S. 1977. Spores of Indian ferns. Today and Tomorrow's Printers and Publishers, New Dehli.

ERDTMAN, G., and P. SoRsA. 1971. Pollen and spore morphology/plant taxonomy. 4. Pteridophyta. Almqvist \& Wiksell, Stockholm.

HiLl, C. R., and J. CAmus. 1986. Evolutionary cladistics in Marattialean ferns. Bull. Brit. Mus. (Nat. Hist.), Bot. 14:219-244.

MORUCCHIO, G. B. 1973. Osservazioni palinologiche sulle "Marattiales." Webbia 28:479-489.

ROLLERI, C. 1993. Revision of the genus Christensenia. Amer. Fern J. 83:3-19.

Rolleri, C., A. M. DefErrari, and M. LaVAlle. 1994. Epidermis y estomas porociclocítos en Christensenia cuingiana Christ (Marattiales). Revista Mus. La Plata, Secc. Bot., n.s. 14:149166.

Tryon, A. F., and B. Lugardon. 1990. Spores of the Pteridophyta. Springer-Verlag, New York. 